Nicole Ritz • Roland A. Ammann •

Carmen Casaulta Aebischer .

Franziska Schoeni-Affolter - Martin H. Schoeni

\title{
Risk factors for allergic bronchopulmonary aspergillosis and sensitisation to Aspergillus fumigatus in patients with cystic fibrosis
}

Published online: 23 May 2006

(C) Springer-Verlag 2006

\section{Eur J Pediatr (2005) 164:577-582}

In the article about risk factors for allergic bronchopulmonary aspergillosis and sensitisation to Aspergillus fumigatus in patients with cystic fibrosis several mistakes in Table 2 were detected.

Table 2 should read as follows.

The basic content of the paper is not affected by this correction.

The authors apologize for this inconvenience and acknowledge the help and critics by Prof. Dr. Sabina Gallati, who determined the genotypes in her laboratory in the Department of Pediatrics, University of Berne, Switzerland, according to the method described in: Liechti-Gallati S, Schneider V, Neeser D, Kraemer R, Two buffer PAGE system-based SSCP/HD analysis: a general protocol for rapid and sensitive mutation screening in cystic fibrosis and any other human genetic disease. Eur. J. Hum. Genet. 1999;7:590-8, and who informed us about the inconsistent listing of the genotypes.
Table 2 Distribution of CFTR alleles in cases with ABPA, AFS and their control groups (Pearsons $\chi^{2}=10.6$, exact $p=0.30$ )

\begin{tabular}{|c|c|c|c|c|}
\hline CFTR alleles & ABPA & ABPA control & AFS & AFS control \\
\hline Patients (n) & $(n=11)$ & $(n=25)$ & $(n=20)$ & $(n=37)$ \\
\hline$\Delta \mathrm{F} 508$ & $18(82 \%)$ & $43(86 \%)$ & $31(78 \%)$ & $49(66 \%)$ \\
\hline 3905 ins T & $0(0 \%)$ & $1(2 \%)$ & $4(10 \%)$ & $7(9 \%)$ \\
\hline R553X & $1(5 \%)$ & $2(4 \%)$ & $1(3 \%)$ & $7(9 \%)$ \\
\hline \multirow[t]{12}{*}{ others } & $3(14 \%)$ & $4(8 \%)$ & $4(10 \%)$ & $11(15 \%)$ \\
\hline & $1717+1 \mathrm{G}>\mathrm{A}$ & $\mathrm{R} 347 \mathrm{P}$ & 2176insC & G126D \\
\hline & 1199 delG & $2347 \mathrm{delG}$ & G542X & G542X \\
\hline & R560S & Q525X & Q525X & E585X \\
\hline & & 3732 delA & N1303K & $4005+1 G>A$ \\
\hline & & & & M1101K \\
\hline & & & & K710X \\
\hline & & & & Q525X \\
\hline & & & & $621+1 \mathrm{G}>\mathrm{A}$ \\
\hline & & & & 3732delA \\
\hline & & & & N1303K \\
\hline & & & & $2789+5 \mathrm{G}>\mathrm{A}$ \\
\hline
\end{tabular}

The online version of the original article can be found at http://dx. doi.org/10.1007/s00431-005-1701-4

\footnotetext{
N. Ritz - R. A. Ammann - C. Casaulta Aebischer ·

M. H. Schoeni $(\square)$

Department of Paediatrics, University of Berne,

3010 Berne, Switzerland

e-mail: martin-heinrich.schoeni@insel.ch

Tel.: +41-31-6329443

Fax: +41-31-6329416

F. Schoeni-Affolter

Department of Embryology, University of Fribourg,

Fribourg, Switzerland
} 